Instructions for authors, subscriptions and further details:

http://brac.hipatiapress.com

\title{
Presencias de lo Cotidiano. Objetos y Creatividad en el Arte Moderno y Contemporáneo: Aproximación al Caso de Antoni Tàpies
}

Albert Macaya ${ }^{1}$

1) Universitat Rovira i Virgili, Tarragona (España)

Date of publication: February $3^{\text {rd }}, 2016$

Edition period: February 2016 - June 2016

To cite this article: Macaya, A. (2015). Presencias de lo cotidiano. Objetos y creatividad en el arte moderno y contemporáneo: aproximación al caso de Antoni Tàpies. Barcelona, Research, Art, Creation, 4(1), 50-64. doi: 10.17583/brac.2016.1831

To link this article: http://dx.doi.org/10.17583/brac.2016.1831

\section{PLEASE SCROLL DOWN FOR ARTICLE}

The terms and conditions of use, except where otherwise noted, are related to the Open Journal System and to Creative Commons Attribution License (CCBY). The indication must be expressly stated when necessary. 


\section{Daily Life Presences. Objects and Creativity in Modern and Contemporary Art: Notes on Antoni Tapies}

Albert Macaya

Rovira i Virgili University, Tarragona (España)

(Received: 2 December 2015; Accepted: 25 December 2015; Published: 3 February 2016)

\section{Abstract}

Daily life objects have been present in modern and contemporary art, in the creative process of many artists as much as in artworks themselves. Links between art and objects are multidimensional and have enabled some of the most interesting experiences in recent art. In this paper, we will examine the dimensions that objects have acquired in the work of artists. We will outline two major directions in what concerns the use of objects in recent art: on the one hand, the gazes that show us daily life objects on a new way and, on the other, the works that bring objects into a sort of language game, giving new significance to them. After a summary review of several references in the art of the past, we will focus on the use of objects in the work of Antoni Tapies, in order to explore an interesting net of possible nexus between objects and a diversity of signification modes and cultural forms.

Keywords: Contemporary art, object-art, creativity in visual arts 


\title{
Presencias de lo Cotidiano. Objetos y Creatividad en el Arte Moderno y
} Contemporáneo: Aproximación al Caso de Antoni Tàpies

\author{
Albert Macaya \\ Universidad Rovira i Virgili, Tarragona (España)
}

(Recibido: 2 Diciembre 2015; Aceptado: 25 Diciembre 2015; Publicado: 3 Febrero 2016)

\section{Resumen}

Los objetos de uso cotidiano, en el arte moderno y contemporáneo, han formado parte tanto del proceso creativo como de las propias producciones de numerosos artistas. La relación entre objetos y creatividad es multidimensional y ha dado lugar a algunas de las más sugerentes propuestas artísticas de las últimas décadas. En este artículo, se analizan las distintas dimensiones y sentidos que ha adquirido los objetos en el quehacer de los artistas. Esbozamos dos grandes direcciones en la presencia de objetos en el arte reciente: la de las miradas a objetos cotidianos que los hacen aparecer bajo una nueva luz, y la que involucra a un determinado objeto en un juego de significados en que éste adquiere sentidos totalmente nuevos.

Tras un breve repaso de algunos referentes históricos, nos centramos en el caso de la presencia de objetos en el trabajo de Antoni Tàpies, que nos permitirá explorar un rico entramado de relaciones posibles de los objetos con modos de significado y formas culturales diversas.

Palabras clave: Arte contemporáneo, arte objetual, creatividad artística, Tapies

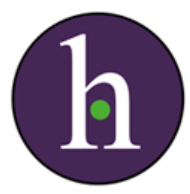




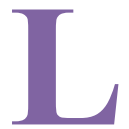

as artes visuales han mantenido, históricamente, un indudable vínculo con la creatividad, vínculo que ha sido alimentado por los artistas con las más diversas estrategias. Una interesante veta donde indagar, para los creadores visuales a la hora de potenciar sus recursos creativos, ha sido el universo de los objetos que les rodean. Los objetos que acompañan nuestra vida cotidiana, las cosas que forman parte de nuestro quehacer habitual, han sido reinterpretados y reinventados en las artes visuales con resultados muy diversos. Esta presencia de objetos en el arte se ha puesto al servicio de las más variadas empresas: mimesis y metáfora de la fugacidad de la vida en el bodegón barroco, reinterpretación formal en las vanguardias, concreción material de juegos de significado en el arte conceptual. En cualquier caso, desde la relectura formal a la radical descontextualización o la búsqueda de significados posibles, pasando por el descubrimiento de asociaciones sorprendentes y novedosas, los objetos han cobrado vidas impensadas en manos de los artistas, han emprendido, a veces, un viaje de posibilidades en que nadie antes había reparado.

En este artículo repasaremos algunos hitos significativos (sin el ánimo de exhaustividad académica que permitiría, tal vez, un trabajo más extenso) de la relación del arte y los artistas con los objetos centrándonos en experiencias desarrolladas en el siglo XX y XXI. Pondremos el acento en el papel de los objetos tanto como catalizadores del proceso creativo como en su dimensión de elementos integrantes de la obra final. Tomaremos como ejemplo en que concretar la reflexión inicial el trabajo de Antoni Tàpies. Y, finalmente, propondremos algunas conexiones que se derivan de su aproximación a los objetos hacia formas artísticas y culturales múltiples. El análisis de estas conexiones tendrá dos puntos de llegada. Por un lado, Tàpies, como muchos otros artistas, ha propuesto miradas nuevas sobre los objetos, nos ha mostrado su poética desde una perspectiva nueva, en la estela de la máxima de Paul Klee de hacer visible lo invisible. Por otro lado, la presencia del objeto en Tàpies ejemplifica la diversidad de juegos de significado que desvela el hecho de integrar objetos de la vida cotidiana en la obra artística mediante mecanismos como la descontextualización o la metonimia, recursos ampliamente desarrollados en la postmodernidad. Y, finalmente, el objeto en Tàpies nos remite también a su conocido interés por tradiciones culturales no occidentales, mucho antes de la expansión masiva de la fascinación por lo 
multicultural.

\section{Objetos y Creación Artística: Una Larga Historia}

El entramado de ideas esbozado en los párrafos precedentes podría quizá organizarse alrededor de dos ideas-fuerza. Por un lado, tenemos las propuestas artísticas que muestran objetos cotidianos bajo una nueva luz, que los reinterpretan o que proyectan sobre ellos una mirada singular, renovada. Por otro, las obras que involucran al objeto en un juego mas o menos complejo de significados, que lo embarcan en una aventura conceptual determinada.

La primera opción tiene un punto de anclaje teórico que ha sido muy influyente en la reflexión estética durante décadas, si bien en los últimos años cuenta tal vez con menos adeptos. Nos referimos a la idea heideggeriana de la dimensión ontológica de la obra de arte. Heidegger $(1935 ; 1996)$, pese a considerar el carácter material, objetual de la obra de arte, destaca no obstante su dimensión de verdad. Una obra de arte tiene peso, volumen, materia, es una cosa, sustancia dotada de propiedades, un conjunto de materia y forma. Pero no es un objeto sin más. Algo determinante la distancia del objeto-útil, del utensilio. Heidegger se sirve de un ejemplo ciertamente brillante: nos remite a Van Gogh, que representa en 1886 un par de zapatos de campesino. Sabemos que unos zapatos son un útil, un objeto marcado por la servicialidad, algo a que su propietario recurre cuando las necesita. La conocida pintura de Van Gogh representando unos zapatos de campo nos hace pensar, además, en la pertenencia de este útil a la tierra, al mundo de experiencia vivida de su propietario, el campesino que los experimenta como algo cercano y fiable. Por tanto, la experiencia que nos proporciona la pintura de Van Gogh no es la mera representación de una cosa. Transciende con mucho la literalidad de unos zapatos para mostrar su verdad: "En la obra de arte se ha puesto en obra la verdad del ente. 'Poner' significa aqui: llevar a estar (zum Stehen bringen). Un ente, un par de zapatos campesinos, viene en la obra de arte a estar en el claro de su ser. El ser del ente viene a lo permanente de su brillar" (Heidegger, 1996, p. 33).

Este "estar en claro" del ente nos permite vislumbrar que, para Heidegger, el arte, aunque se materialice y forme parte del mundo, inaugura un mundo; es una puesta en obra de la verdad.

Otra idea seminal para el arte moderno y contemporáneo, que nos será útil para explorar la segunda opción en el uso de los objetos en el arte que 
planteábamos, ha sido la de los Juegos del Lenguaje. Como es sabido, debemos la expresión a Wittgenstein $(1953 ; 2008)$ que, en el contexto del llamado "giro pragmático" de su obra de madurez, explora el significado como la actividad que tiene lugar en el marco de una comunidad lingüística, más allá de la univocidad del lenguaje declarativo que enfatizaba el "primer" Wittgenstein . El significado de un término cobra sentido en el modo en que éste es utilizado por los hablantes, admite diversos usos en diferentes contextos. Wittgenstein se opone a la idea de expresión como algo que esta en la mente individual y se expresa por medios visuales o verbales.

A esta idea del significado privado que se comparte cuando se explicita, opone una concepción intersubjetiva, afirmando que el significado de una palabra es su uso. Foster (2006) ha visto en los juegos de lenguaje uno de los argumentos que guiaron la reacción al expresionismo abstracto por parte de artistas como Jasper Johns o Andy Warhol. La estética del pop art, que incorpora objetos de la cultura de masas desposeídos de toda intencionalidad "expresionista", opone a la idea de expresión subjetiva una estética de la indiferencia (Roth, 1998). Obviamente, no podemos dejar de pensar en el antecedente duchampiano, máxime en una reflexión centrada en el uso del objeto en el arte reciente. Mucho antes de la publicación de "investigaciones filosóficas" en 1953, Duchamp habia planteado un radical "juego de lenguaje" con el readymade a partir de 1913, en que, entre otras cosas, forzaba los límites del lenguaje de las artes visuales. Juego que, al igual que propone Foster en relación a la generación de Warhol, va acompañado por una indiferencia estética. En palabras del propio Duchamp (2012), la elección de la rueda de bicicleta y el taburete fue guiada por "una reacción de indiferencia visual, adecuada simultáneamente a una ausencia total de buen o mal gusto... de hecho una anestesia completa." Cabria añadir que esta radical renuncia al componente retiniano (por emplear la expresión del propio Duchamp) del arte fue retomada como un argumento de reacción al formalismo de la primera mitad del siglo XX, en la estela de Benjamin (1936; 2003) y su conocida formulación del arte post-aurático. La incorporación de objetos de uso común a las propuestas artísticas de las últimas décadas podría ser pues interpretada en el contexto de esa voluntad de liquidar el aura de unicidad del arte del pasado, incluido el sello (en otro tiempo casi mágico) que imprime "la mano del artista". El aura benjaminiana deja paso, en la afortunada expresión de Brea (1991), a las auras frías o, en último término, al llamado "post-arte".

Cabría pues trazar dos líneas de continuidad en el uso de los objetos en 
las artes visuales emparentadas con las ideas que hemos bosquejado, esto es: objetos cotidianos que, en virtud de su reinterpretación artística, adquieren una dimensión totalmente nueva, siendo el anclaje sensorial que "inaugura un mundo", y objetos que nos retan a explorar los significados posibles que contienen y que nos embarcan en juegos de lenguaje siempre renovados.

Las cajas de Oteiza, las Herramientas Inútiles de Martín Chirino o algunas obras de Antoni Tàpies podrían ejemplificar la primera posibilidad. La segunda incluiría sin duda a Duchamp y Warhol, pero también buena parte del arte conceptual y sus derivaciones en el cambio de siglo XX-XXI.

\section{Los Objetos como Compendio y Manifiesto}

En cualquier caso, no es difícil señalar ejemplos de cómo el universo de objetos de que se han rodeado artistas y escritores ha actuado como catalizador de su actividad creativa. Bastaría evocar la autorepresentación de David Bailly en su estudio (1645) para pensar en todo un mundo de wunderkammer y gabinetes de curiosidades en que no pocos artistas se han apoyado para excitar su imaginación. Un magnífico ejemplo seria el estudio de André Breton, hoy reproducido en el Centre Pompidou de París, un abigarrado cúmulo de muebles de época, artefactos étnicos, mascaras, pinturas y dibujos. Inmediatamente se piensa en la mesa de trabajo de D'Annunzio o de Gómez de la Serna, repletas de objetos e imágenes de diversa índole. Objetos atesorados y dispuestos con pulcritud por su propietario como los siurells, cántaros y construcciones con hoja de palma en la Masia de Son Boter de Miró, o montañas informes de papeles y artefactos en el mítico estudio de Joan Brossa en la barcelonesa calle Balmes.

La pulsión de atesorar objetos e imágenes que seduce a tantos artistas tiene quizá una raíz en común con dos de los proyectos intelectuales más singulares de las primeras décadas del siglo XX: el museo imaginario de André Malraux y el Atlas Mnemosine de Aby Warburg. El primero, un museo sin sede, un lugar mental en el que las obras artísticas se relacionan y conectan entre si desposeídas de contexto, un museo en que las obras se "cuelgan y descuelgan a un ritmo imprevisible" (Malraux, 1947; 1956, p. 33) y que bien podría estar poblado de reproducciones fotográficas en lugar de objetos reales. El segundo, un quimérico compendio de cultura visual de épocas y lugares diversos que pretendía evidenciar constantes universales en la historia de las imágenes. En 
los proyectos de Malraux y Warburg se intuye la misma necesidad de explorar elementos visuales con los que se experimenta un determinado vínculo, la misma proximidad que experimentan los artistas con sus particulares colecciones de objetos.

Antoni Tàpies se presenta en la segunda parte de este trabajo como "caso de estudio" particularmente significativo de la línea argumental que estamos siguiendo. Hemos esbozado, unos párrafos más arriba, la relación de los compendios de imágenes de Warburg y Malraux con las colecciones de objetos con que se rodean algunos artistas como via de inmersión en terrenos creativos. Tàpies ensambla las dos ideas.

En 2010 la fundación Tàpies reabrió sus puertas tras una reforma con una propuesta expositiva, que tuvo también su versión en formato libro unos años antes: Los lugares del arte, un heteróclito compendio de obras artísticas propiedad del artista, objetos tribales, libros científicos, que el propio Tàpies (1999) definió como un particular "museo-manifiesto", una suerte de hábitat mental y creativo en el que se definía en imágenes su universo de intereses. El proyecto tenia un antecedente directo en un articulo del propio Tàpies, publicado en Vogue en 1992, titulado “Trois mille ans d'amitiés". El artista reúne imágenes y objetos de diversas épocas y estilos artísticos y los presenta como un "manifiesto visual". Los lugares del arte amplia y perfecciona la fórmula. Las imágenes y objetos reunidos por Tàpies parecen desplegar su máxima elocuencia cuando renunciamos a contextualizarlas en una cronología o un cuadrante de estilos artísticos y autorías. Cuando dejamos de ver un torso de estatua Khmer, una caja de madera japonesa, una virgen románica mutilada o una máscara senufo, empezamos realmente a intuir el universo Tàpies, auténtico hilo argumental del relato de los lugares del arte. Discurso en imágenes o imágenes sin texto: resulta sugerente releer la propuesta a la luz de tendencias contemporáneas como la denominada Art Based Research, que explora la posibilidad de plantear un ensayo en imágenes con la misma densidad conceptual que atribuimos habitualmente al discurso escrito; tendencia que reivindica, en último término, la consideración del arte como un formato de conocimiento válido también el ámbito académico (Barone y Eisner, 2014). 


\section{La Tradición del Arte Objetual en el Arte Moderno y Contemporáneo: Notas para una Cronología}

Un repaso en profundidad de la tradición objetual en las artes requeriría, sin duda, un estudio mucho más extenso del que podemos desarrollar aquí, y que poco podría aportar a la erudición de trabajos ya existentes. No podemos, sin embargo, dejar de aludir a algunos referentes significativos para la línea argumental de este texto. Como hemos apuntado, el antecedente más conocido en cuanto a la presencia de objetos en el arte es sin duda Duchamp y sus célebres ready made. Pero, cronológicamente, habría que hacer referencia antes a Picasso y a Braque. Picasso será el primero en integrar un objeto en una obra pictórica: Naturaleza muerta con silla de rejilla (1912). Picasso introdujo un hule, un material plástico estampado, y creó el marco del cuadro con una cuerda de cáñamo. Asistimos así al advenimiento del collage, es decir, la creación de una obra con materiales elaborados previamente, idea emparentada con el hilo discursivo de este artículo. Tal tipo de obra tendrá continuación en los papiers collés de Braque.

El paso definitivo, sin embargo, lo daría Marcel Duchamp. El readymade es entre otras cosas, un radical ejercicio de descontextualización. Los readymade han sido considerados como el inicio del llamado arte objetual, y han tenido consecuencias de largo alcance en el arte contemporáneo. Quizá sin saberlo, Duchamp trazó lo que seria una larga línea de continuidad. Planteó un contundente cuestionamiento del arte aurático a la vez que abrió una vía fructífera a los dadaístas y a los surrealistas. El objet trouvé surrealista retoma la experiencia duchampiana hibridándola con la conocida aserción de Lautreamont "Bello como el encuentro fortuito de una máquina de coser y un paraguas sobre una mesa de disección". Así nacen algunas creaciones objetuales ya clásicas como el teléfono-langosta de Dalí (1936), la taza peluda de Meret Oppenheim en Le déjeuner en fourrure (1936), los lápices e imperdibles en el rostro de Les calanques (1942) de Picabia o la plancha con clavos en Le cadeau (1921) de Man Ray.

En los años cincuenta, en Nueva York, donde aun vivía y trabajaba Marcel Duchamp, Robert Rauschemberg y Jaspers Johns retomaron en cierto modo el mismo juego. Rauschembreg creó a su manera una suerte de readymade: Cama (1955), en el que utilizó ropa de cama que salpicó de pintura. Tres años más tarde creó Coca-Cola Plan, una pieza escultórica en la que integró tres botellas de Coca-cola que, por cierto, pasaron a ser uno de los motivos mas 
sococorridos del arte pop.

Crow (2014) ha remarcado la conexión entre estos trabajos y la generación del pop art. Pensemos en Andy Warhol y sus famosas cajas Brillo. En este caso Warhol hacia una representación del objeto tan parecida al original que es difícil distinguir entre el objeto real y el objeto construido. Danto (2009) ha enfatizado la trascendencia de la propuesta warholiana al generar una confusión entre el arte y la realidad, confusión que inaugura lo que será una larga veta en el arte contemporáneo.

El arte pop tomó sus objetos de la cotidianidad, pero en un nuevo contexto: el del hiperconsumo americano, en el que la posesión de todo tipo de artículos parecía poco menos que una de las finalidades esenciales de la vida. La publicidad tuvo un peso importantísimo en la cultura pop. Una publicidad que no solo mostraba de forma atractiva los objetos sino que pretendía convencer al receptor de que eran indispensables. Algunos artistas de la órbita pop, como Oldenburg, sitúan a los objetos en el centro mismo de su temática.

Por esos mismos años, en Europa, surge una nueva generación de creadores en torno a la figura del crítico Pierre Restany. El grupo estaba integrado por Klein, Arman, Spoerri, Tinguely, Hains, Raysse y Villeglé, a los que se unen pronto César, Niky de Saint-Phalle, Christo y Deschamps. Estos artistas también exploran las posibilidades creativas de los objetos de uso cotidiano. Al igual que los artistas pop, parte de su programa era alejarse de los informalistas y dejar atrás el trabajo "de propia mano" del artista. César cede a la prensa industrial la tarea de aplastar los coches y materiales de desguace, Niki de Saint-Phalle deja a la pistola que haga los cuadros, Klein al fuego o a otras personas, Tinguely deja a la máquina que pinte. Arman propone acumulaciones de objetos. Spoerri integra platos y cubiertos, herramientas, muebles.

Más allá de las experiencias del Noveau Realisme, la presencia de los objetos en el arte reciente adquiere una nueva orientación con la entrada en escena de un amplio desbordamiento de las prácticas artísticas a partir de la década de 1960. Para evitar incidir en argumentos muy sabidos, como la disolución de los géneros artísticos convencionales y la hibridación de medios y disciplinas artísticas, nos limitaremos a evocar la ya clásica one and tree chairs (1965) de Kosuth como obra seminal de toda una nueva estética que se abre a una amplísima nómina de creadores. Ya no nos sorprenderán, pues, los neumáticos de Allan Kaprov, los relojes y displays electrónicos de Tatsuo Miyajima, los botes, cajas y embalajes en Marcel Brothaers o Piero Manzoni, los artículos de supermercado pulcramente dispuestos en los estantes de Haim 
Steinbach unos años mas tarde. Ya no hablamos de objetos integrados en obras de artistas convencionales, ahora se trata mas bien de fragmentos de realidad en crudo como parte integrante de propuestas artísticas, quizá en la estela del viejo sueño Fluxus de fusionar arte y vida.

\section{Apuntes para un Estudio de Caso: El Objeto en la Obra de Antoni Tàpies}

En los párrafos precedentes hemos apuntado la diversidad de vías de integración de los objetos cotidianos en el entorno y en la propia obra de una gran diversidad de artistas. Un caso especialmente sugerente podría ser el de Antoni Tàpies, que desde obras tan lejanas cronológicamente como Puerta y violín (1956), Paja prensada en X (1969), Paja y madera (1969) o Columna de periódicos (1970), incorporó objetos y materiales de uso común en su producción artística. Según la interpretación acaso más habitual, Tàpies encuentra en los objetos una plasmación de un elemento tan central en su poética como es la trascendencia de lo humilde, la unidad existente entre lo espiritual y lo material. Moure (1990) subrayó que sus obras objeto están cerca de la experiencia inmediata, sin haberla tenido que despojar de apariencia alguna. Así mismo, Borja-Villel (1990) convendría en que Tàpies utilizaba estos objetos cotidianos libres de toda sospecha narrativa y en los que dado su carácter anodino es su puro estar-ahí, su pura presencia lo que se hace patente.

Sin embargo, caben otro tipo de aproximaciones. Tàpies es un artista obviamente emparentado con el informalismo europeo pero que parece haber sido sensible a las corrientes neodadaistas y povera de los 60 y los 70 e incluso a las tendencias conceptuales posteriores. Una afirmación como esta podría ser seriamente cuestionada desde la perspectiva del debate en la escena artística barcelonesa de los años 70 y primeros 80 del siglo pasado. La emergencia de las propuestas conceptuales en la escena catalana, fundamentalmente alrededor del Grup de Treball, supuso, en su momento, una reacción al magisterio de los clásicos de la tardomodernidad pictórica, particularmente encarnada en el propio Tàpies. Se ha hablado, incluso, de una cierta querelle entre informalistas y conceptuales en la segunda mitad de los 70. Afirmar pues que hay en Tapies algo así como una voluntad conceptual puede parecer una idea de alto riesgo. Y sin embargo, esta es la tesis que defendió Godfrey (2013), en el contexto de la exposición Antoni Tàpies, del objeto a la escultura (1964-2009) en el Guggenheim de Bilbao. Portc (2013) relacionó las obras objetuales de Tàpies con algunas propuestas presentes en 
When attitudes become form, la ya mítica exposición comisariada por Harald Szeemann en la Kunsthalle de Berna en 1969, tales como los sacos de cereales de Iannis Kounellis, los ladrillos en el agua de Giovanni Anselmo, la cuerda de Barry Flannagan o el teléfono de Walter de Maria. Por su parte, BorjaVillel (1990) destaca también como a partir de unas primeras experiencias con objetos en los 60 y primeros 70, el interés renovado por los objetos cotidianos en el Tàpies de madurez coincide con las preocupaciones del povera europeo y del arte post-minimalista americano. Señala asimismo la conexión entre obras objetuales de Tapies y las corrientes de signo simbolista o místico. Paja y madera (1969) es explicada por el propio Tapies (1971) a partir de los mitos védicos en que el fuego llega al mundo a través de una chispa solar que prende en un haz de paja. En este punto, Borja-Villel sugiere también la conexión con Beuys. Ambos serian artistas que, en consonancia con la figura del chaman tan grata a Beuys, descubren la naturaleza de los materiales y dan sentido a la vida.

\section{Conexiones}

Como hemos apuntado en la introducción de este texto, los objetos en la obra de Tàpies se prestan a constituir un entramado de relaciones posibles, de las que sólo examinaremos aquí algunas particularmente sugerentes.

Tapies apuntó algunas pistas interesantes para comprender las múltiples resonancias de los objetos que aparecen en su obra. Catoir (1998) nos señala también una dirección sugerente: el interés del artista por el bodegón barroco. Como es sabido, el barroco desplegó una extraordinaria variedad de narrativas contrapuestas, contradictorias incluso. El bodegón holandés, poblado de mesas exuberantes, cargadas hasta el exceso de frutas, viandas y caza, poco tiene que ver con el bodegón español; o, por lo menos, con un cierto bodegón que es el que impresiona a Tàpies: las austeras ventanas de Sánchez Cotán, donde parecen levitar frutas y hortalizas extrañamente suspendidas en cordeles, las pulcras disposiciones de objetos cotidianos de Juan Van der Hamen, y, cómo no, los soberbios y esenciales bodegones de Zurbarán. A diferencia de las opulentas naturalezas muertas de los Países Bajos, el barroco español proyecta una mirada de alta intensidad sobre los objetos, una mirada más próxima a la contemplación ensimismada que a la sensualidad de Pieter Claesz o Willem Claeszoom Heda. En la mirada casi alucinada de un Sánchez Cotán se adivina 
un nexo con la percepción alterada de la realidad propia de la mística del siglo de oro. Cabe citar un pasaje de los escritos de la monja Cecilia del Nacimiento en que describe los estados de alteración de la conciencia que preceden al éxtasis. Los objetos se presentan con una intensidad especial a la mirada. Así describe esa consciencia intensificada de lo real: "En este tiempo miraba todas las cosas con tan gran viveza, que parece las penetraba con unos ojos de lince hasta las entrañas por un modo extraño, y me hacía algunas veces tal fuerza lo que conocía en ellas de Dios, que parecía insufrible" (citada por Barbeito, 2007). Tàpies se ha referido a menudo a su intención de proyectar una mirada nueva sobre los objetos, en particular los más humildes e insignificantes, para, a la manera de la advaitia (no dualidad) del pensamiento tradicional hindú, descubrir la secreta conexión que une lo banal y lo trascendente. La visión de las cosas "con tan gran viveza" de que habla Cecilia de Nacimiento no esta muy alejada del estado de darana o concentración máxima que describe Coomaraswami (2006), uno de los referentes clásicos en la reflexión estética sobre el arte indio, como condición para la creación artística. Plantea el ejemplo de un pasaje del Ramayana, en que se narra como Valmiki, ante la empresa de representar a la divinidad, se entrega a una serie de rituales de purificación y a la practica Yoga, y consigue finalmente ver "con toda claridad" a Rama, Lakhsmi y Sita "como quien ve una fruta nelli en la palma de su mano". Y concluye:

En cualquier lugar de oriente, donde el pensamiento hindú o budista haya calado lo suficiente, existe la convicción de que la mente concentrada y orientada a un punto, tiene acceso directo a toda clase de conocimiento sin necesidad de la intervención directa de los sentidos. Es probable que todos los artistas hayan tenido más o menos contacto con esta realidad a través de sus experiencias personales. (Coomaraswami, 2006, p. 25)

La referencia al pensamiento estético indio nos allana el camino a otra noción de raíz oriental muy presente el la obra y los escritos de Tapies: el universo Zen. El propio artista ha establecido un claro paralelismo entre el Zen y su propia actividad creativa:

En el Zen hay un lado meditativo, pero también está el choque que sirve para sacudir el pensamiento, para hacer algo más bien indigerible. Hay momentos en que realmente soy muy contemplativo y me diluyo en el 
vacío. Pero también están aquellos momentos en que intento, en otro caso, sugerir el vacío con una sacudida y desvelar así al espectador. (Tapies, citado por Julian, 2012)

La querencia de la estética Zen por lo imperfecto, incompleto, gastado, irregular, por los objetos de uso cotidiano más simples y austeros, que acusan el paso del tiempo, tiene una relación suficientemente manifiesta con las preocupaciones de Tàpies. Dos ideas muy difundidas entre nosotros de la estética Zen son las categorías wabi y sabi. Mientas que sabi seria algo así como el ensimismamiento que alguien experimenta ante las formas de la naturaleza, wabi se refiere a la complacencia en la irregularidad, la asimetría, la imperfección. La noción de wabi impregna buena parte del arte japonés de los últimos cuatro siglos. Podemos rastrearla en la textura y las grietas del rakú, en la áspera simplicidad de los jardines de grava o en la imprecisión y espontaneidad de contornos del trazado de un enso o una caligrafía a punta de pincel. La pintura sumi-e, sobre todo en el caso de sus practicantes más radicales como Musahi o Sengai-Gibon, se complace también en la espontaneidad, la simplicidad y los espacios en blanco. Representa la realidad con una audacia desconocida hasta el momento, pero esa audacia tiene como paso previo la total interiorización del tema a representar. Actitud que remite a la contemplación del iniciado en el Zen, que, observando un objeto cualquiera (el ejemplo clásico seria una vela), detiene el flujo incesante del pensamiento y alcanza una nueva dimensión de consciencia. He aquí una posible línea "genealógica" de la que derivaría la apuesta de buen número de artistas occidentales por la simplicidad y lo mínimo, en la estela de la vieja divisa de Mies van der Rohe: menos es más.

De modo análogo, las diversas manifestaciones estéticas afines al Zen, como en el caso del propio Tàpies, nos retan a comprobar como la contemplación y la densidad de la experiencia nos abren la puerta a otro modo de lucidez. En palabras del artista,

Amar las cosas en su mortalidad, comprender que todo ha de cambiar irremisiblemente. Quizá por sentir yo también ese amor por las cosas huidizas siempre me ha parecido absurdo en el arte occidental todo cuanto represente lo contrario: la abundancia o la fabricación en serie, los materiales demasiado sólidos o demasiado tecnificados (...). Nosotros ya casi no sabemos ver las cosas ni tenemos tiempo para ello. Los sentidos nos resbalan sobre el exceso de preocupaciones, de coloridos, de 
aturdimientos y de ruidos que siempre nos rodean. Debemos conquistar y aprender lo más primordial: poder y saber contemplar, poder y saber concentrarnos en lo que hacemos, tener tiempo para meditar, tener un mínimo de decencia y de libertad en nuestras vidas. (Tàpies, 1971)

Tàpies trata de trazar un arco que va desde la presencia humilde y perecedera de las cosas hasta la intuición de lo trascendente. Mostrarnos la fisicidad de los objetos y hacernos reconocer, en ellos, su energía evocadora, su carga simbólica o las resonancias que apelan a la experiencia vivida. De la concreción de la materia hasta la abstracción de lo inefable sin solución de continuidad.

\section{Referencias}

Barbeito, M. I. (2007). Mujeres y literatura del Siglo de Oro: espacios profanos y espacios conventuales. Madrid : Safekat

Barone, T. y Eisner, E. W. (2014). Arts Based Research. Los Angeles: SAGE Benjamin, W. (2003). La obra de arte en la época de su reproductibilidad técnica. México: Itaca

Borja - Villel, M. (1990): Arte y transgresión en la obra de Antoni Tàpies, en VV. AA.: Tapies, extensiones de la realidad. Madrid: Centro de Arte Reina Sofía.

Brea, J. L. (1991). Las auras frias. Madrid: Anagrama Catoir, B. (1998). Converses amb Antoni Tàpies. Barcelona: Polígrafa Coomaraswami, A. (2006). La danza de Siva. Madrid: Siruela Crow, T. E. (2014). The Long march of pop: art, music and design, 19301995. New Haven: Yale University Press

Danto, A. C. (2009). Andy Warhol. New Haven: Yale University Press. Duchamp, M. (2012). Escritos. Barcelona: Galaxia Gutemberg Foster, H., Krauss, R., Bois., A., Bucloh, B. (2006): Arte después de 1900. Madrid: Akal

Godfrey, T. (2013). Tàpies y el arte conceptual. ¿Enemigos o amigos secretos? En VV. AA., Antoni Tàpies, del objeto a la escultura (19642009). Bilbao: Museo Guggenheim Heidegger, M. (1996). El origen de la obra de arte. Madrid: Alianza Julian, I. (2012). Conversaciones con Tàpies. Barcelona: Barataria 
Malraux, A. (1956). Las voces del silencio. Visión del arte. Buenos Aires: Emecé

Moure, G. (1990). Antoni Tàpies: los objetos como concreciones del devenir,

VV. AA.: Tapies, extensiones de la realidad. Madrid: Centro de Arte Reina Sofía.

Portc, M. (2013). Una gran masa maravillosa. En VV. AA., Antoni Tàpies, del objeto a la escultura (1964- 2009). Bilbao: Guggenheim

Roth, M. (1998). Difference/Indifference: Musings on Postmodernism, Marcel Duchamp and John Cage. New York: Routledge

Tàpies, A.(1971). La práctica del arte. Barcelona: Ariel

Tàpies, A. (1999). El arte y sus lugares. Madrid: Siruela

Wittgenstein, L. (2008). Investigaciones Filosóficas. Madrid: Crítitca

\footnotetext{
Albert Macaya: Universitat Rovira i Virgili.

Contact Address: Universitat Rovira i Virgili. Carrer de l'Escorxador, s/n, 43003 Tarragona (España).

E-mail address: albert.macaya@urv.cat
} 